\title{
Hydrothermal Growth and Hydrogen Selective Sensing of Nickel Oxide Nanowires
}

\author{
Thi Thanh Le Dang, Matteo Tonezzer, and Van Hieu Nguyen \\ International Training Institute for Materials Science (ITIMS), Hanoi University of Science and Technology (HUST), No. 1, \\ Dai Co Viet Street, Hanoi 100000, Vietnam \\ Correspondence should be addressed to Thi Thanh Le Dang; thanhle@itims.edu.vn
}

Received 7 July 2015; Accepted 15 September 2015

Academic Editor: Thierry Baron

Copyright (C) 2015 Thi Thanh Le Dang et al. This is an open access article distributed under the Creative Commons Attribution License, which permits unrestricted use, distribution, and reproduction in any medium, provided the original work is properly cited.

\begin{abstract}
Low cost synthesis of nanostructured metal oxides for gas sensing application at low temperature is nowadays of crucial importance in many fields. Herein, $\mathrm{NiO}$ p-type semiconducting nanowires with polycrystalline structure were prepared by a facile and scalable hydrothermal method. Morphology and crystal structure of the NiO nanowires were investigated by scan electron microscopy, $\mathrm{X}$-ray diffraction, and transmission electron microscopy. The nanostructured material was then tested as hydrogen sensor showing very good performance in terms of sensor response, stability, absence of drifts, and speed of response and recovery. The selectivity of the $\mathrm{NiO}$ sensor to hydrogen towards other gases (ethanol, ammonia, and liquefied petroleum gas) was found to be good.
\end{abstract}

\section{Introduction}

Metal oxides are very good sensing materials. In the last decade, metal oxide nanostructures have been extensively studied in order to optimize them for several applications, including gas sensing. Semiconducting n-type metal oxides (mainly $\mathrm{SnO}_{2}$ and $\mathrm{ZnO}$ ) have been investigated as gas sensing material very deeper than their p-type counterparts. Recently, also p-type metal oxides are being studied, and among them nickel oxide (NiO). Tuning the size and shape of nanostructured materials is a commonly employed strategy to optimize their performance due to their structuredependent properties [1-3]. Nanowires, one of the quasimonodimensional (1D) nanostructures, are perfect building blocks for functional nanodevices and represent the smallest dimension for efficient electron and hole transport [4]. As an important $\mathrm{p}$-type semiconductor with wide band gap energy in the range of 3.6-4.0 eV [5], $\mathrm{NiO}$ has been considered as a promising material due to its excellent chemical stability and pronounced electrical properties with potential applications in a wide range of fields, including catalysis [6], electrode materials for lithium ion batteries [7], photovoltaic devices [8], fuel cell electrodes, electrochemical supercapacitors [9], electrochromic films [10], magnetic materials [11], and gas sensors [12-14]. To date, various $\mathrm{NiO}$ nanostructures have been grown, including nanoparticles [15], nanorods [16], nanotubes [17], and nanosheets [18].
Many growth methods such as aqueous solution [19, 20], electrochemical deposition [21, 22], vapor-based metal etching oxidation method [23], and dehydration method [24] have been used to fabricate $\mathrm{NiO}$ nanowires. However, most of the deposition techniques used require strict parameters like high temperature, high vacuum, and complex reactions, leading to expensive processes and preventing a wide use of these materials. Compared to other methods, hydrothermal synthetic method has attracted the broadest attention for its simple operation and low power consumption.

Herein, we report on the growth of nickel oxalate hydrate $\left(\mathrm{NiC}_{2} \mathrm{O}_{4} \cdot 2 \mathrm{H}_{2} \mathrm{O}\right)$ nanowires by the hydrothermal method and their thermal decomposition during calcination at $500^{\circ} \mathrm{C}$, obtaining polycrystalline $\mathrm{NiO}$ nanowires. Morphology and structure of the nickel oxide nanowires are characterized, and their gas sensing properties to detect hydrogen gas are investigated.

\section{Materials and Methods}

2.1. Synthesis of Nickel Oxide Nanowires. The $\mathrm{NiO}$ nanowires have been grown via a two-step deposition consisting in a hydrothermal method followed by an annealing at $500^{\circ} \mathrm{C}$. All the chemicals used in our experiments were of analytical reagent grade and were directly used without further purification. In a typical procedure, $0.474 \mathrm{~g}$ of $\mathrm{NiCl}_{2} \cdot 6 \mathrm{H}_{2} \mathrm{O}$ 
(Sigma-Aldrich, Germany) was dissolved into a mixture of $32 \mathrm{~mL}$ ethylene glycol (EG, Sigma-Aldrich) and $18 \mathrm{~mL}$ deionized water in a beaker under continuous magnetic stirring at room temperature. Then $0.1206 \mathrm{~g}$ of $\mathrm{Na}_{2} \mathrm{C}_{2} \mathrm{O}_{4}$ was added into the beaker. Half an hour of continuous magnetic stirring was carried out to ensure that $\mathrm{Ni}^{2+}$ ions were dispersed homogeneously in the solution. The clear solution was transferred into a Teflon-lined stainless steel autoclave of $100 \mathrm{~mL}$ capacity. The autoclave was sealed and heated at $200^{\circ} \mathrm{C}$ for $24 \mathrm{~h}$. After the heating treatment, the autoclave was let cooling to room temperature naturally. The product was collected by centrifugation, washed three times with deionized water and absolute ethanol, respectively, and then dried naturally in air. As a result, a blue-green product was obtained.

The polycrystalline $\mathrm{NiO}$ nanowires were obtained by the calcination of this blue-green precursor, consisting in nickel oxalate hydrate $\left(\mathrm{NiC}_{2} \mathrm{O}_{4} \cdot 2 \mathrm{H}_{2} \mathrm{O}\right)$ short nanowires, at $500^{\circ} \mathrm{C}$.

The as-prepared material and the calcinated nanowires were characterized and analyzed by using X-ray diffraction (XRD), scanning electron microscopy (SEM). The XRD analysis was performed using a Bruker D5005 X-ray diffractometer with $\mathrm{CuK}_{\alpha 1}$ radiation $(\lambda=1.5406 \AA)$ at $40 \mathrm{kV}$ and $40 \mathrm{~mA}$. SEM images were obtained using a JEOL7600 scanning electron microscope at an accelerating voltage of $20 \mathrm{kV}$. Transmission electron microscopy (TEM) and electron diffraction images of the calcinated material were obtained using a JEOL JEM-2100 transmission electron microscope at an accelerating voltage of $200 \mathrm{kV}$.

2.2. Sensing Devices Fabrication. The fabrication of sensing devices consists of a 2-step procedure. First, $1 \mathrm{mg}$ of asprepared nickel oxide nanowires was dispersed in ethanol solution under ultrasonic vibration for $3 \mathrm{~min}$. The solution was then dropped onto interdigitated comb $\mathrm{Pt} / \mathrm{Ti}$ electrodes on thermally oxidized silicon substrate. The interdigitated $\mathrm{Pt} / \mathrm{Ti}$ contacts were previously deposited onto the $\mathrm{SiO}_{2} / \mathrm{Si}$ substrates by sputtering and conventional optical lithography technique. The whole device is $2 \mathrm{~mm} \times 6 \mathrm{~mm}$, while the two electrodes consisted in 18 pairs of fingers, each $800 \mu \mathrm{m}$ long and $20 \mu \mathrm{m}$ wide. The gap between two contiguous fingers is $50 \mu \mathrm{m}$. After the deposition of nickel oxide nanowires, the sensor was heated to $500^{\circ} \mathrm{C}$ at a rate of $1.0^{\circ} \mathrm{C} \mathrm{min}^{-1}$ in a furnace and then maintained for $2 \mathrm{~h}$ in order to increase stability and adhesion between active material and metal electrodes.

2.3. Gas Sensing Measurements. The $\mathrm{NiO}$ nanowires sensing properties were measured in dynamic conditions, in which the dilution (dry air) and the tested gas were flowing continuously through the sensing chamber at a total flow rate of $500 \mathrm{sccm}$. The apparatus was home-built and included a test chamber, a sensor holder which can be heated up to $500^{\circ} \mathrm{C}$, and mass flow controllers (connected to high purity calibrated bottles).

The sensors resistance was measured using a Keithley 2400 multimeter connected to a data acquisition system (LabView, National Instruments). The samples, biased with a voltage of $5 \mathrm{~V}$ and operated in air, showed a good ohmic behaviour, with a negligible metal-semiconductor junction resistance. The sensor response $S$ was defined as $S=\left(R_{\text {gas }}-\right.$ $\left.R_{\text {air }}\right) / R_{\text {air }} \cdot 100$, where $R_{\text {gas }}$ and $R_{\text {air }}$ are the resistance of the device in the presence of analyte gas (reducing) or without it, respectively. Response and recovery times are defined as the time needed to reach $90 \%$ of the response value at its maximum and to get down to $10 \%$ of it, respectively.

\section{Results and Discussion}

3.1. Nanowires Characterization. The hydrothermal growth produces thin nanowires with a diameter of about $60 \mathrm{~nm}$. Figure 1(a) shows a SEM image of the grown material: the nanostructures are thin and straight with a constant diameter and smooth surfaces. Their aspect ratio (ratio between length and diameter) depends on the process temperature, increasing while the temperature augments. Once the material (nickel oxalate hydrate nanowires) is calcinated at $500^{\circ} \mathrm{C}$ for 2 hours, the nanowires morphology greatly changes, as shown in Figure 1(b).

It is clear that, after the higher temperature annealing, the nanowires material conglomerates in a series of nanoparticles which still resemble the former nanowires. The nanoparticles are roundish with a diameter in the range of $20-50 \mathrm{~nm}$. A confirmation about the composition of the nanowires before and after the calcination is given by the X-ray diffraction spectra shown in Figure 2. In Figure 2(a), relative to the nanowires before calcination, all the numerous diffraction peaks can be assigned to reflections of monoclinic $\mathrm{NiC}_{2} \mathrm{O}_{4} \cdot 2 \mathrm{H}_{2} \mathrm{O}$ (JCPDS 25-0581). Figure 2(b), relative to nanowires after the calcination process, shows instead a well crystallized cubic $\mathrm{NiO}$ phase (JCPDS 47-1049). The three intense diffraction peaks at $37.3,43.4$, and $62.9^{\circ}$ can be indexed to its cubic unit cell, with a lattice parameter of $4.1667 \AA$. The absence of peaks for any impurity phase in both spectra of Figure 2 confirms that the nanostructures are pure crystals and that the $\mathrm{NiC}_{2} \mathrm{O}_{4} \cdot 2 \mathrm{H}_{2} \mathrm{O}$ precursor was completely converted to $\mathrm{NiO}$ during calcination.

The crystal structure of the $\mathrm{NiO}$ nanowires was further characterized by TEM and high-resolution TEM analysis. Figure 3(a) shows a TEM image of a bundle of $\mathrm{NiO}$ nanowires with diameters ranging from 40 to $70 \mathrm{~nm}$; the whole bundle has a diameter of $600 \mathrm{~nm}$. The high magnification TEM image reported in Figure 3(b) reveals that the nanowires are assembled from $\mathrm{NiO}$ nanoparticles with the diameters of $20-$ $80 \mathrm{~nm}$, with interspaces between the nanoparticles.

The spacing between lattice fringes in Figure 3(b) measures about $0.20 \mathrm{~nm}$, which corresponds to the interplanar distance of (200) lattice planes of cubic NiO. The selected area electron diffraction (SAED) pattern corresponding to the nanogranular $\mathrm{NiO}$ nanowires is reported in Figure 3(c), displaying three diffused rings. These rings are assigned to (111), (200), and (220) diffraction lines of cubic NiO phase, respectively. These investigations reveal that the $\mathrm{NiO}$ nanowires are made of polycrystalline $\mathrm{NiO}$ with cubic structure.

3.2. Gas Sensing Properties. A voltage ranging from $-5 \mathrm{~V}$ to $+5 \mathrm{~V}$ was applied to the sensors to check the electrical contact 


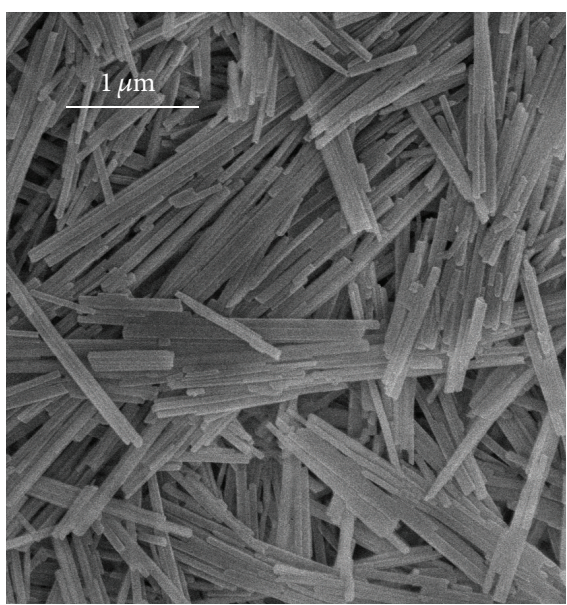

(a)

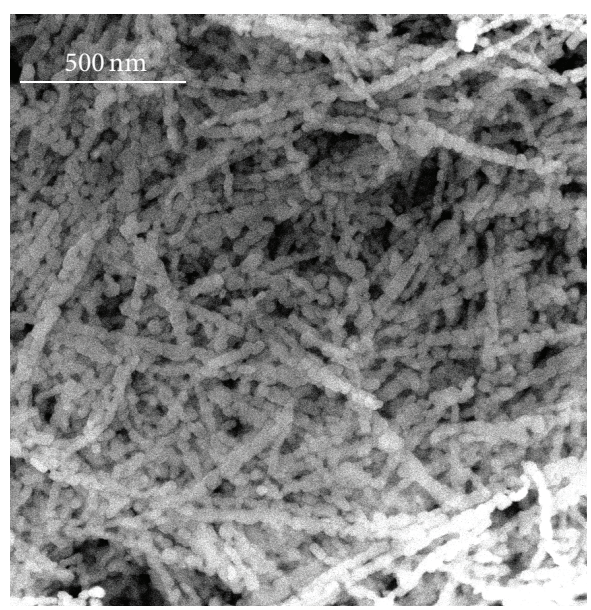

(b)

FIGURE 1: SEM images of the nanowires (a) before and (b) after the calcination at $500^{\circ} \mathrm{C}$.

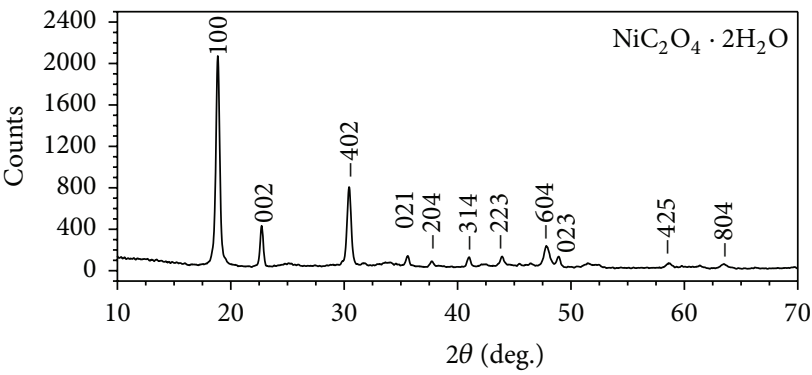

(a)

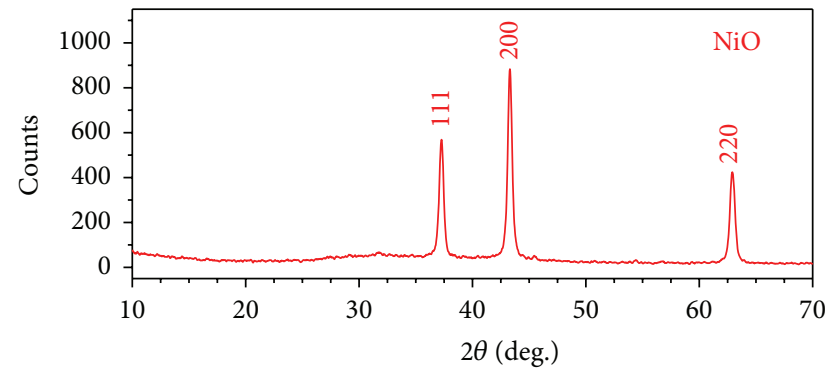

(b)

FIGURE 2: XRD spectra of nanowires (a) before and (b) after the calcination at $500^{\circ} \mathrm{C}$.

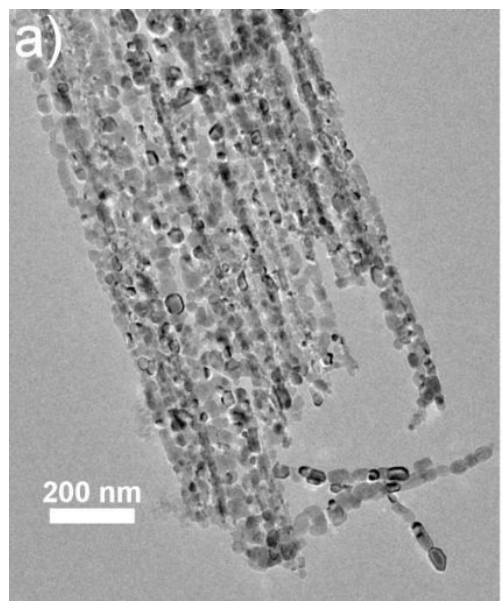

(a)

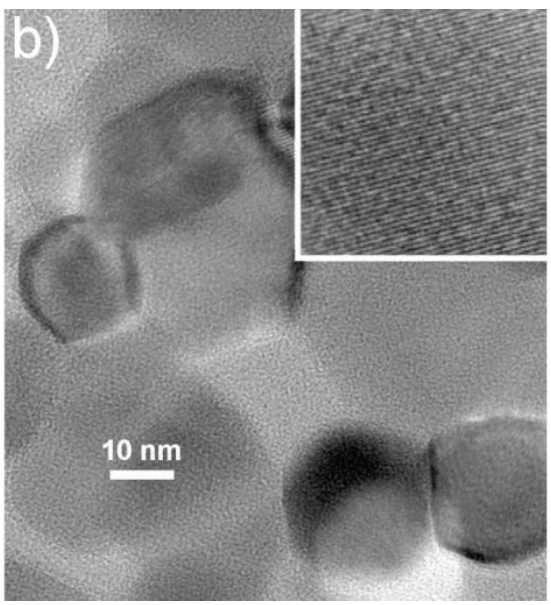

(b)

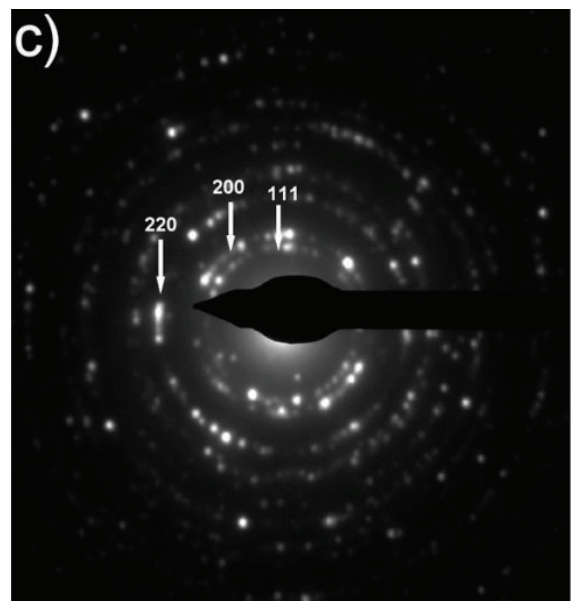

(c)

FIgURE 3: (a) TEM, (b) HRTEM, and (c) SAED images of the nanowires once calcinated. The inset in (b) shows a magnification of the lattice fringes of a nanograin.

between the active material and the metal electrodes. A very good ohmic behaviour was observed, which is important for the sensing properties since the sensor response of a conductometric device can be maximized when the metalsemiconductor connection has a negligible junction resistance. The resistance of the sensors ranged from $27 \mathrm{k} \Omega$ to
$3 \mathrm{M} \Omega$ in air while the temperature increases from 200 to $400^{\circ} \mathrm{C}$. The sensing performance of the $\mathrm{NiO}$ devices was studied at a voltage of $5 \mathrm{~V}$ between the electrodes while flowing different gas concentrations into the apparatus.

Figure 4 shows the dynamic resistance of a sensor to different hydrogen concentrations $(50,100,250,500$, and 

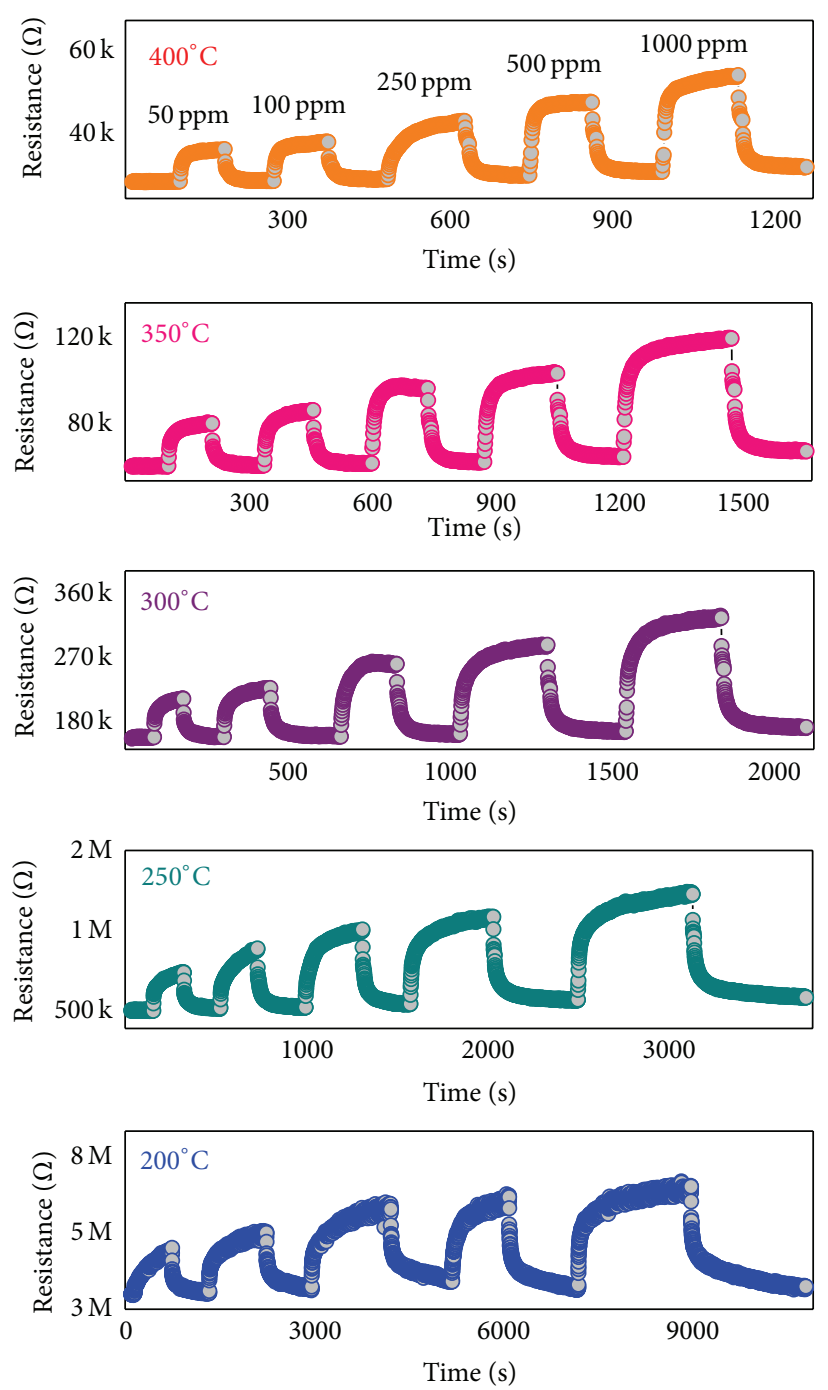

Figure 4: Dynamic resistance of a sensor to the injection and evacuation of different hydrogen concentrations at different sensors working temperatures. Please notice that the $x$-axis presents a different time scale for each plot.

$1000 \mathrm{ppm})$ at different working temperatures $(200,250,300$, 350 , and $\left.400^{\circ} \mathrm{C}\right)$. All the plots show that the resistance of the $\mathrm{NiO}$ nanowires is stable in air and increases when hydrogen gas is injected into the system. When the $\mathrm{H}_{2}$ flow is interrupted and replaced with air, the sensor resistance decreases to its previous value. This behavior well agrees with that of p-type semiconductor sensors. It is indeed well known that $\mathrm{NiO}$ is usually a p-type semiconductor when grown in "normal" conditions. When the $\mathrm{NiO}$ nanowires are exposed to air, oxygen molecules will be absorbed on their surface in the form of $\mathrm{O}^{-}$and $\mathrm{O}^{2-}$. This high coverage with adsorbed oxygen particles drains electrons from the nanostructure, increasing the number of electrical holes and thus enlarging its conductivity in these base conditions. Once hydrogen is flown on the devices, its molecules interact with the adsorbed oxygen releasing the electrons used in the chemical bonds back to the nanowires bulk. This results in a decrease of holes and a rise in the sensor resistance.

As can be seen in Figure 4, the response magnitude of the sensors improves with increasing hydrogen concentration at all working temperatures. At all temperature values, the sensor response is sharp and clear, and the recovery is very good with negligible drifts.

The response values calculated from Figure 4 are reported in Figure 5(a) as a function of $\mathrm{H}_{2}$ concentration. At all temperatures, the sensor response improves with the increasing gas concentration, with a slope (sensitivity) that slowly decreases at high concentrations, indicating the beginning of saturation.

All the curves show a similar trend, with 200 and $250^{\circ} \mathrm{C}$ plots showing the highest response values. A plot of the response values towards the working temperature is indeed reported in Figure 5(b), showing that the best response is always obtained at $200^{\circ} \mathrm{C}\left(50 \mathrm{ppm} \mathrm{H}_{2}\right)$ or $250^{\circ} \mathrm{C}$ (all other hydrogen concentrations). This is a good property of $\mathrm{NiO}$ material compared to other metal oxides, because their sensing properties are usually best at higher temperatures $[32,33]$. The lowest sensor response of $\mathrm{NiO}$ nanowires based sensors goes from $30.4 \%$ to $81.6 \%$ at $400^{\circ} \mathrm{C}$. The best values go from $56.8 \%\left(200^{\circ} \mathrm{C}\right.$ ) to $106.9 \%$ (at $250^{\circ} \mathrm{C}$ ). These values 


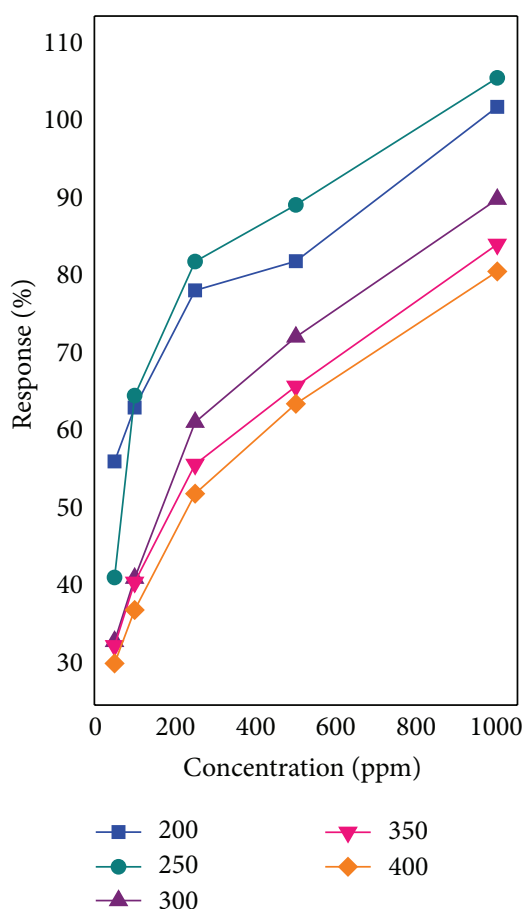

(a)

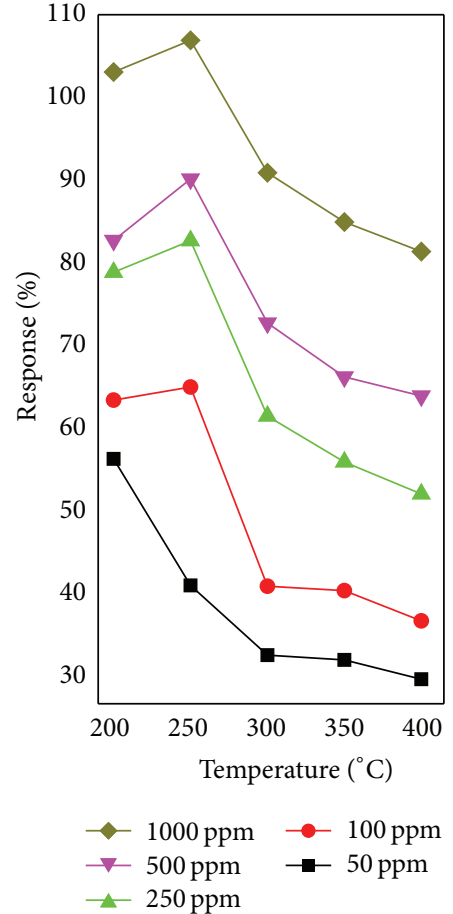

(b)

FIGURE 5: Sensor percentage response as a function of (a) hydrogen concentration and (b) working temperature.

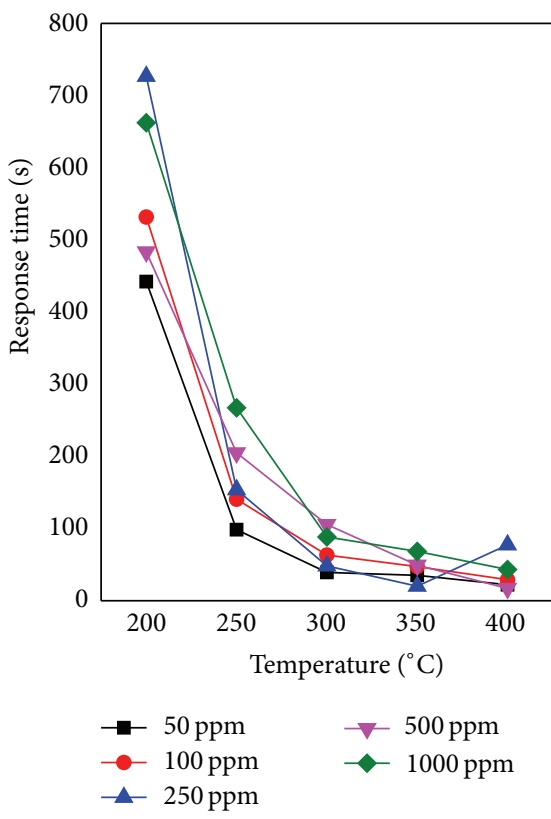

(a)

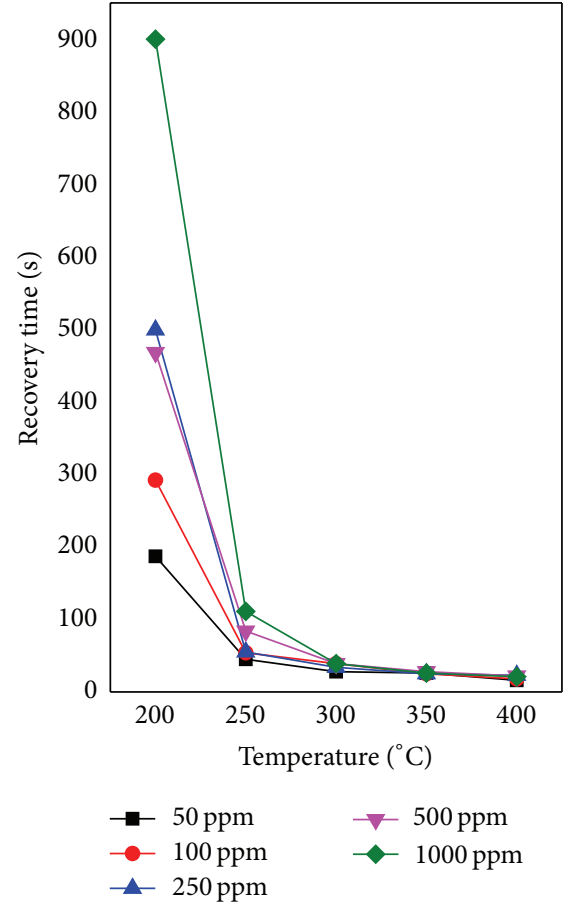

(b)

FIgURE 6: (a) Response time and (b) recovery time values as a function of working temperature for different hydrogen concentrations.

are good when compared with literature, as will be shown in Table 1.

The speed of the response and the recovery of the sensors at different gas concentrations and working temperatures, calculated from Figure 4, are presented in Figure 6.
Figure 6(a) shows response times, while Figure 6(b) shows recovery times. It is clear that both response and recovery times decrease while increasing the working temperature. There is no evident dependency on the hydrogen concentration. The response time goes from hundreds of 
TABLE 1: Percentage response, response time, and recovery time values of sensors presented in this paper, compared with recent literature.

\begin{tabular}{|c|c|c|c|c|c|c|c|}
\hline Note & & $\begin{array}{c}\text { Work } T . \\
{\left[{ }^{\circ} \mathrm{C}\right]}\end{array}$ & $\begin{array}{c}\text { Concentration } \\
{[\mathrm{ppm}]}\end{array}$ & $\begin{array}{c}\text { Percentage } \\
\text { response [\%] }\end{array}$ & $\begin{array}{c}\text { Response } \\
\text { time [s] }\end{array}$ & $\begin{array}{l}\text { Recovery } \\
\text { time }[\mathrm{s}]\end{array}$ & $\begin{array}{c}\text { Reference } \\
\text { (year) }\end{array}$ \\
\hline \multirow{9}{*}{ n-type } & \multirow{2}{*}{ Thin film } & \multirow{2}{*}{125} & \multirow{2}{*}{30000} & 14 & 600 & 540 & \multirow{2}{*}{ [25] (2008) } \\
\hline & & & & 76 & 900 & 600 & \\
\hline & Nanoparticle & 150 & 1000 & 10.8 & & & [26] (2012) \\
\hline & \multirow{2}{*}{ Thin film } & \multirow{2}{*}{300} & 3000 & 29.6 & 404 & & \multirow{2}{*}{ [27] (2013) } \\
\hline & & & 6000 & 45 & & & \\
\hline & \multirow{4}{*}{ Nanoparticle } & 150 & \multirow{4}{*}{3000} & 42.5 & 328 & 450 & \multirow{4}{*}{ [28] (2013) } \\
\hline & & 175 & & 68 & 328 & 1017 & \\
\hline & & 200 & & 62.7 & 200 & 774 & \\
\hline & & 225 & & 49.4 & 243 & 243 & \\
\hline \multirow[t]{9}{*}{ p-type } & & 175 & 1000 & 30 & & & \\
\hline & \multirow{3}{*}{ Thin film } & 160 & 1000 & 3.65 & & & \multirow{3}{*}{ [29] (2015) } \\
\hline & & \multirow{2}{*}{180} & 1000 & 9.1 & & & \\
\hline & & & 2000 & 9.5 & 1980 & 144 & \\
\hline & Nanoparticle & 175 & 1000 & 22.25 & 1164 & 810 & [30] (2012) \\
\hline & Nanoparticle & 175 & 1000 & 32.4 & 134 & 406 & [31] (2012) \\
\hline & \multirow{3}{*}{ Nanowire } & 200 & 1000 & 103 & 659 & 900 & \multirow{3}{*}{ Present work } \\
\hline & & 250 & 1000 & 107 & 266 & 111 & \\
\hline & & 300 & 1000 & 91 & 88 & 39 & \\
\hline
\end{tabular}

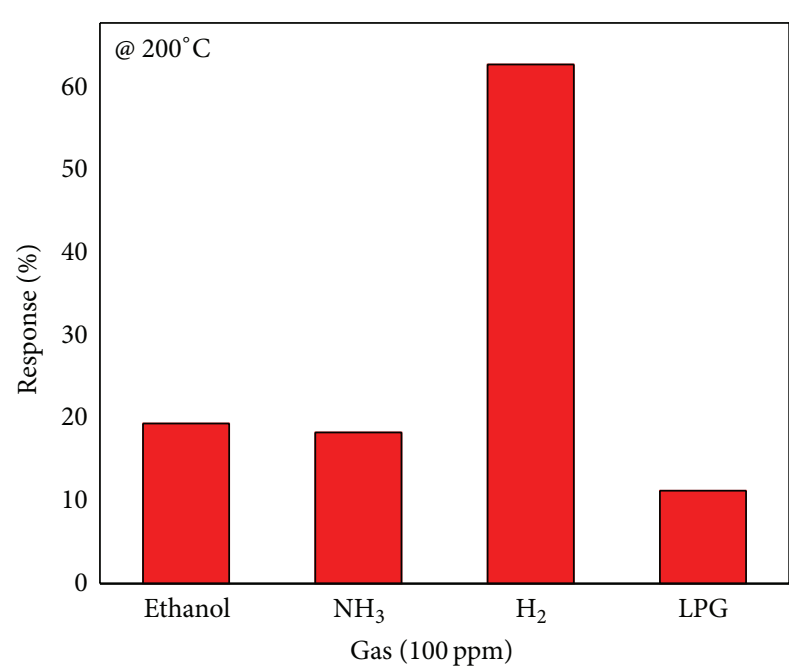

FIgURE 7: Percentage response of a sensor to $100 \mathrm{ppm}$ of ethanol, ammonia, hydrogen, and liquefied petroleum gas at a working temperature of $200^{\circ} \mathrm{C}$.

seconds at $200^{\circ} \mathrm{C}$ to few tens of seconds at $300-400^{\circ} \mathrm{C}$. Similarly, the plot in Figure 6(b) shows an even steeper decrease: the recovery times go from some hundreds of seconds at $200^{\circ} \mathrm{C}$ down to few tens of seconds much more quickly. As can be seen in Table 1, the speed of the sensors presented in this work is good when compared with the present literature.

Selectivity of the $\mathrm{NiO}$ polycrystalline nanowires has been studied towards ethanol, ammonia $\left(\mathrm{NH}_{3}\right)$, and liquefied petroleum gas (LPG). All these gases behaved as reducing gases, increasing the devices resistance upon their injection. Figure 7 reports the response value of the $\mathrm{NiO}$ nanogranular sensors to $100 \mathrm{ppm}$ of different gases while working at $200^{\circ} \mathrm{C}$. It is apparent that hydrogen gives rise to a very high response while compared to ethanol, $\mathrm{NH}_{3}$, and LPG.

At a low temperature of $200^{\circ} \mathrm{C}$, the $\mathrm{NiO}$ sensor gives a response of around $65 \%$ to $\mathrm{H}_{2}$, while the response to ethanol and $\mathrm{NH}_{3}$ is lower than $20 \%$ and that to LPG is lower than $10 \%$. This proves that the $\mathrm{NiO}$ polycrystalline nanowires can be used as selective hydrogen sensors.

\section{Conclusions}

We have grown $\mathrm{NiO}$ polycrystalline nanowires via a simple and cheap process consisting in hydrothermal growth followed by high temperature calcination. The thin polycrystalline nanowires, composed by $\mathrm{NiO}$ nanoparticles, show very good hydrogen sensing properties with response values that exceed $100 \%$, quick response and recovery times (down to tens of seconds at $400^{\circ} \mathrm{C}$ ), and good selectivity to hydrogen against ammonia, ethanol, and liquefied petroleum gas.

\section{Conflict of Interests}

The authors declare that there is no conflict of interests regarding the publication of this paper.

\section{Acknowledgments}

This research is funded by Vietnam National Foundation for Science and Technology Development (NAFOSTED) under 
Grant no. 103.02-2013.23 and by the Italian Ministry of Foreign Affairs and International Cooperation (MAECI) with the Project HyMN. The authors acknowledge to Laboratory of Geology, Geoengineering, Geoenvironment and Climate Change at Vietnam National University, Hanoi for HRTEM characterizations.

\section{References}

[1] B.-Y. Wang, D.-S. Lim, and Y.-J. Oh, "CO gas detection of al-doped $\mathrm{ZnO}$ nanostructures with various shapes," Japanese Journal of Applied Physics, vol. 52, no. 10, Article ID 101103, 2013.

[2] M. Tonezzer and N. V. Hieu, "Size-dependent response of single-nanowire gas sensors," Sensors and Actuators B: Chemical, vol. 163, no. 1, pp. 146-152, 2012.

[3] M. Tonezzer, T. T. L. Dang, N. Bazzanella, V. H. Nguyen, and S. Iannotta, "Comparative gas-sensing performance of 1D and 2D $\mathrm{ZnO}$ nanostructures," Sensors and Actuators B: Chemical, vol. 220, pp. 1152-1160, 2015.

[4] A. Heinzig, T. Mikolajick, J. Trommer, D. Grimm, and W. M. Weber, "Dually active silicon nanowire transistors and circuits with equal electron and hole transport," Nano Letters, vol. 13, no. 9, pp. 4176-4181, 2013.

[5] R. Lo Nigro, S. Battiato, G. Greco, P. Fiorenza, F. Roccaforte, and G. Malandrino, "Metal Organic Chemical Vapor Deposition of nickel oxide thin films for wide band gap device technology," Thin Solid Films, vol. 563, pp. 50-55, 2014.

[6] M. A. Bhosale and B. M. Bhanage, "Rapid synthesis of nickel oxide nanorods and its applications in catalysis," Advanced Powder Technology, vol. 26, pp. 422-427, 2015.

[7] B. Varghese, M. V. Reddy, Z. Y. Yanwu et al., "Fabrication of NiO nanowall electrodes for high performance lithium ion battery," Chemistry of Materials, vol. 20, no. 10, pp. 3360-3367, 2008.

[8] K.-C. Wang, J.-Y. Jeng, P.-S. Shen et al., "p-type mesoscopic nickel oxide/organometallic perovskite heterojunction solar cells," Scientific Reports, vol. 4, article 4756, 2014.

[9] M. Zhou, Y. Deng, K. Liang, X. Liu, B. Wei, and W. Hu, "One-step route synthesis of active carbon@ $\mathrm{La}_{2} \mathrm{NiO}_{4} / \mathrm{NiO}$ hybrid coatings as supercapacitor electrode materials: significant improvements in electrochemical performance," Journal of Electroanalytical Chemistry, vol. 742, pp. 1-7, 2015.

[10] J. Denayer, G. Bister, P. Simonis et al., "Surfactant-assisted ultrasonic spray pyrolysis of nickel oxide and lithium-doped nickel oxide thin films, toward electrochromic applications," Applied Surface Science, vol. 321, pp. 61-69, 2014.

[11] S. D. Tiwari and K. P. Rajeev, "Magnetic properties of $\mathrm{NiO}$ nanoparticles," Thin Solid Films, vol. 505, no. 1-2, pp. 113-117, 2006.

[12] J. A. Dirksen, K. Duval, and T. A. Ring, "NiO thin-film formaldehyde gas sensor," Sensors and Actuators B: Chemical, vol. 80, no. 2, pp. 106-115, 2001.

[13] C.-Y. Lee, C.-M. Chiang, Y.-H. Wang, and R.-H. Ma, "A selfheating gas sensor with integrated $\mathrm{NiO}$ thin-film for formaldehyde detection," Sensors and Actuators B: Chemical, vol. 122, no. 2, pp. 503-510, 2007.

[14] C. Luyo, R. Ionescu, L. F. Reyes et al., "Gas sensing response of $\mathrm{NiO}$ nanoparticle films made by reactive gas deposition," Sensors and Actuators B: Chemical, vol. 138, no. 1, pp. 14-20, 2009.

[15] E. R. Beach, K. Shqau, S. E. Brown, S. J. Rozeveld, and P. A. Morris, "Solvothermal synthesis of crystalline nickel oxide nanoparticles," Materials Chemistry and Physics, vol. 115, no. 1, pp. 371-377, 2009.

[16] N. Srivastava and P. C. Srivastava, "Synthesis and characterization of (single- and poly-) crystalline $\mathrm{NiO}$ nanorods by a simple chemical route," Physica E: Low-Dimensional Systems and Nanostructures, vol. 42, no. 9, pp. 2225-2230, 2010.

[17] S. A. Needham, G. X. Wang, and H. K. Liu, "Synthesis of $\mathrm{NiO}$ nanotubes for use as negative electrodes in lithium ion batteries," Journal of Power Sources, vol. 159, no. 1, pp. 254-257, 2006.

[18] Z.-H. Liang, Y.-J. Zhu, and X.-L. Hu, " $\beta$-nickel hydroxide nanosheets and their thermal decomposition to nickel oxide nanosheets," Journal of Physical Chemistry B, vol. 108, no. 11, pp. 3488-3491, 2004.

[19] Y. Zhan, C. Zheng, Y. Liu, and G. Wang, "Synthesis of NiO nanowires by an oxidation route," Materials Letters, vol. 57, no. 21, pp. 3265-3268, 2003.

[20] L. Wu, Y. Wu, H. Wei, Y. Shi, and C. Hu, "Synthesis and characteristics of $\mathrm{NiO}$ nanowire by a solution method," Materials Letters, vol. 58, no. 21, pp. 2700-2703, 2004.

[21] Y. Lin, T. Xie, B. Cheng, B. Geng, and L. Zhang, "Ordered nickel oxide nanowire arrays and their optical absorption properties," Chemical Physics Letters, vol. 380, no. 5-6, pp. 521-525, 2003.

[22] K. Nielsch, F. Müller, A.-P. Li, and U. Gösele, "Uniform nickel deposition into ordered alumina pores by pulsed electrodeposition," Advanced Materials, vol. 12, no. 8, pp. 582-586, 2000.

[23] Z. P. Wei, M. Arredondo, H. Y. Peng et al., "A template and catalyst-free metal-etching-oxidation method to synthesize aligned oxide nanowire arrays: $\mathrm{NiO}$ as an example," ACS Nano, vol. 4, no. 8, pp. 4785-4791, 2010.

[24] H. Pang, Q. Lu, Y. Zhang, Y. Li, and F. Gao, "Selective synthesis of nickel oxide nanowires and length effect on their electrochemical properties," Nanoscale, vol. 2, no. 6, pp. 920922, 2010.

[25] M. Stamataki, D. Tsamakis, N. Brilis, I. Fasaki, A. Giannoudakos, and M. Kompitsas, "Hydrogen gas sensors based on PLD grown NiO thin film structures," Physica Status Solidi (A) Applications and Materials Science, vol. 205, no. 8, pp. 20642068, 2008.

[26] Y. Du, W. Wang, X. Li et al., "Preparation of NiO nanoparticles in microemulsion and its gas sensing performance," Materials Letters, vol. 68, pp. 168-170, 2012.

[27] I. Garduño-Wilches and J. C. Alonso, "Hydrogen sensors fabricated with sprayed $\mathrm{NiO}, \mathrm{NiO}$ : $\mathrm{Li}$ and $\mathrm{NiO}: \mathrm{Li}, \mathrm{Pt}$ thin films," International Journal of Hydrogen Energy, vol. 38, no. 10, pp. 4213-4219, 2013.

[28] A. M. Soleimanpour, Y. Hou, and A. H. Jayatissa, "Evolution of hydrogen gas sensing properties of sol-gel derived nickel oxide thin film," Sensors and Actuators, B: Chemical, vol. 182, pp. 125$133,2013$.

[29] I. Sta, M. Jlassi, M. Kandyla et al., "Hydrogen sensing by solgel grown $\mathrm{NiO}$ and $\mathrm{NiO}: \mathrm{Li}$ thin films," Journal of Alloys and Compounds, vol. 626, pp. 87-92, 2015.

[30] A. M. Soleimanpour and A. H. Jayatissa, "Preparation of nanocrystalline nickel oxide thin films by sol-gel process for hydrogen sensor applications," Materials Science and Engineering C, vol. 32, no. 8, pp. 2230-2234, 2012.

[31] A. M. Soleimanpour, S. V. Khare, and A. H. Jayatissa, "Enhancement of hydrogen gas sensing of nanocrystalline nickel oxide by pulsed-laser irradiation," ACS Applied Materials and Interfaces, vol. 4, no. 9, pp. 4651-4657, 2012. 
[32] C. Wang, L. Yin, L. Zhang, D. Xiang, and R. Gao, "Metal oxide gas sensors: sensitivity and influencing factors," Sensors, vol. 10, no. 3, pp. 2088-2106, 2010.

[33] M. Tonezzer and S. Iannotta, " $\mathrm{H}_{2}$ sensing properties of twodimensional zinc oxide nanostructures," Talanta, vol. 122, pp. 201-208, 2014. 

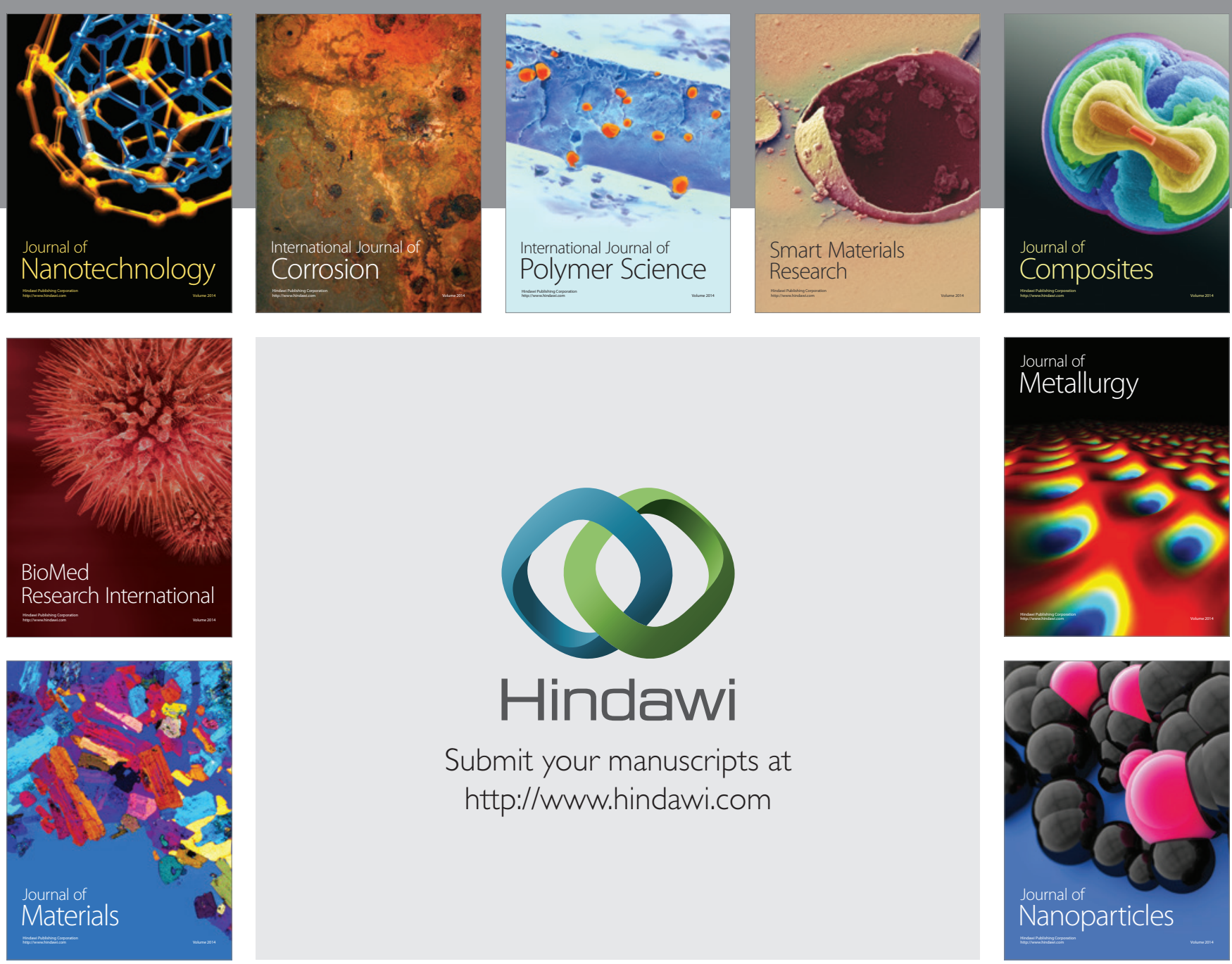

Submit your manuscripts at http://www.hindawi.com
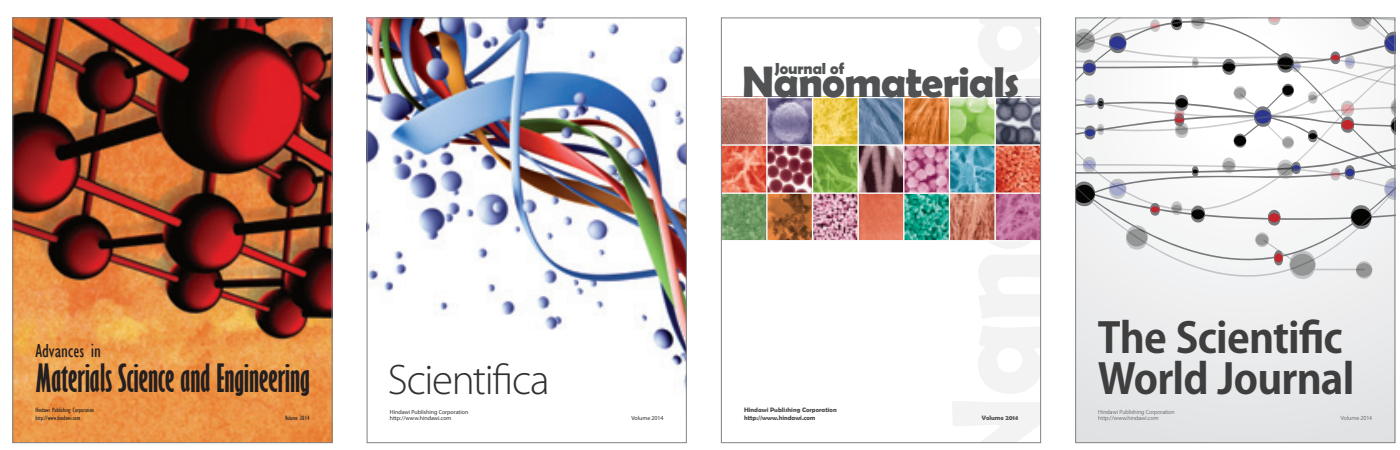

\section{The Scientific World Journal}
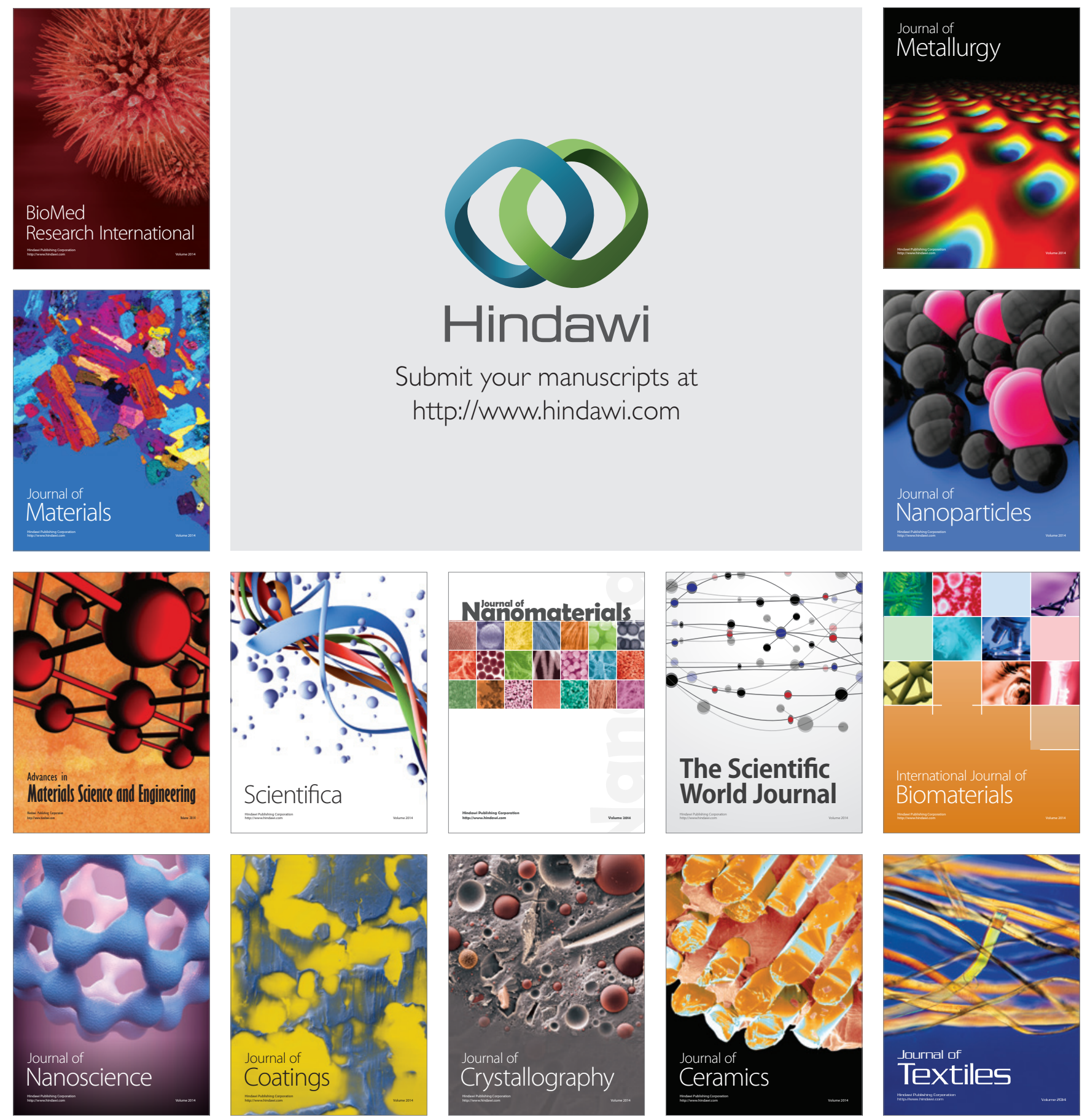